\title{
Depression in seniors vs. their nutritional status and nutritional knowledge
}

\author{
Rafał W. Wójciak', Ewa Mojs', Halina Staniek², Katarzyna Marcinek², Ewelina Król², \\ Joanna Suliburska², Zbigniew Krejpcio ${ }^{2}$ \\ ${ }^{1}$ Department of Clinical Psychology, Poznan University of Medical Sciences, Poland \\ 2 Food Hygiene and Toxicology Chair, Department of Human Nutrition and Hygiene, Poznan University of Life Sciences
}

\begin{abstract}
Aim. There is a limited amount of data on depression in elderly people and even less is known about the relationship between nutritional status and nutritional habits, and mood disorders in this group. The foregoing paper investigates this relationship and evaluates the family status of seniors with depression.

Material and methods. The research was conducted on a group of 85 seniors in the ages of 60-91 years. The depression symptoms, nutritional knowledge and nutritional status were investigated and their relationship in elderly women.

Results. Depression was present in $27 \%$ of women. Seniors with depression had a significantly lower BMI and a larger number of them had better nutritional knowledge than the rest of women. Women with the lowest BMI were statistically younger, had better nutritional knowledge and higher level of depression than women with normal BMI. There is a relationship between depression and family status of seniors. A significantly larger number of single women suffered from depression (50\%) in comparison with women in relationships (25\%) and single widows (23\%).

Conclusions. Research showed that there is a relationship between symptoms of depression in elderly women with nutrition and family status. Extending research in order to evaluate nutrition disorders in seniors, which influence their mood disorders seems justified.
\end{abstract}

Key words: women, seniors, depression, nourishment.

\section{Introduction}

Civilization progress, particularly in the field of medicine, treatment and illness prevention, led to the increase of life expectancy $[1,2]$. At the same time due to the recent decrease in the population growth in well-developed countries the number of elderly people in the general population increases [1, 2].

Demographic data indicate that $25 \%$ of people worldwide and $50 \%$ of people in Europe will reach the age of 65 in the next 50 years [2-4]. 14\% of people living in Poland in 2013 have reached 65 [2] and it is estimated that this number will reach $21 \%$ within the next 10 years $[4,5]$.
With age the human state of health slowly deteriorates, which means that old age is very often characterized by somatic multisymptom illnesses brought about both by pathological symptoms or resulting from the physiological process of aging [6-8]. Among the main causes of disorders in the elderly age there are problems with nutrition, caused by changes in the metabolism and problems with chewing and digesting the food $[8,9]$. One of the most difficult challenges for the elderly people is changing their eating habits, which is necessary if they want to stay healthy $[8,10$, 11]. A different structure of food, different methods of preparing food, regular meals and their taste are 
all elements that should be considered in their everyday diet and which require proper knowledge about healthy nutrition. There is little information about the seniors' level of knowledge about proper nutrition. However it should be mentioned that nutritional preferences of the elderly are often the wrong ones. They may lead to health disorders, such as overweight and obesity, high blood pressure, heart diseases, hypercholesterolemia, etc. [10, 12]. On the other hand scientific research fails to mention that more and more elderly people are either over- or underweight. This may be caused by disorders in digesting and absorbing food, as well as by problems with chewing, lack of taste, new cooking methods, which the elderly find unacceptable. Psychological factors should also be considered. Peoples' attitude towards old age, loneliness or the need to face their disabilities are the source of fear, paranoid disorders, dementia or depression [1, 3, 5, 13, 14].

Depression is a group of emotional disorders that may intensify when accompanied by somatic disorders. Depression is characterized by the strong feeling of fear, lowering the mood and physical activity. It is estimated that depression, next to dementia, is the most commonly diagnosed mental disorder in the elderly. It is diagnosed in about $15 \%$ of people over $65[2,7]$. Depression in the elderly people often leads to disability, impairing their quality of life and causing premature death, as well as suicides $[1,2,15]$. It is mainly caused by loneliness after losing the life partner, an empty nest syndrome, the feeling of uselessness or suffering caused by disability $[1,2,15,16]$. In the last few years it has also been found that depression may be related to quantitive and qualitative malnutrition [17-20]. Anaemia caused by iron deficiency may particularly influence certain mood disorders [6, 17 , 19]. Even $65 \%$ of elderly people may have low iron levels, thus suffering from anaemia [6]. So far scientists have not been particularly interested in investigating the relationship between depression in an elderly age with proper nourishment and the level of knowledge about nourishment. It seems that it may have an influence on initiating the foregoing disease and on its prevention.

\section{Aim}

The aim of this preliminary research was an attempt to evaluate the occurrence of depression in elderly women and its relations to their nutritional status and nutritional knowledge.

\section{Materials and methods}

Research was conducted on a group of 85 seniors in the ages from 60 to 91 (average $73.3 \pm 9.0$ years) residing in big cities (over 50 thousand inhabitants) in the Wielkopolska area. People participating in the study were divided into three groups based on their age (60-70 years - 37 women, $70-80$ years 25 women and above 80 years - 2 women). After explaining the purpose of research and obtaining the consent of the participants, they were first weighed and measured (medical scales with accuracy to $1 \mathrm{~cm}$ and $1 \mathrm{~g}$ respectively). Anthropometric measurements were used to calculate the Quetelet's index - mass to height (Body Mass Index; BMI), based on which the nourishment condition of the participants was evaluated. The proper value was between 18.5 and 24.9 $\mathrm{kg} / \mathrm{m}^{2}$ [17]. Next, seniors were asked to fill out a questionnaire which contained the GAROTA nutritional knowledge test [21]. 42 questions with three levels of difficulty, which represented all sections were randomly selected from all the questions in the survey. Taking into consideration the age of the applicants, only multiple choice questions were selected and evaluated in the scale from 0 to 1 . The average level of knowledge was determined as $50-70 \%$ of proper answers (22-30 points). Depression was also evaluated based on the Geriatric Depression Scale (GDS). People with the score above 10 points in the GDS test, which indicated light depression and above 20 points - indicating deep depression, underwent an individual psychological diagnosis based on the ICD-10 depression criteria, which helps to determine the occurrence and level of depression $[15,16]$. To evaluate the family status women were divided into those living alone (including single women that were never in a relationship and widows living alone), and those living with partners.

To evaluate the significance of differences between the average values a t-Student test was used, while distribution was evaluated with the $\chi 2$ test.

\section{Results}

Table 1 presents average results of the evaluated parameters. The average BMI index in seniors was within normal range $\left(24.1 \pm 4.5 \mathrm{~kg} / \mathrm{m}^{2} ; 16.5-36.8 \mathrm{~kg} / \mathrm{m}^{2}\right)$ and was similar in particular age groups. The average result of the GDS test showed no signs of depression in the examined groups (8.2 $\pm 6.2 ; 0-24)$, regardless of age. The seniors' level of nutritional knowledge was average (GAROTA test - $24.2 \pm 3.6$; 17-33). Nutritional knowl- 
Table 1. Average results of analysed parameters in seniors

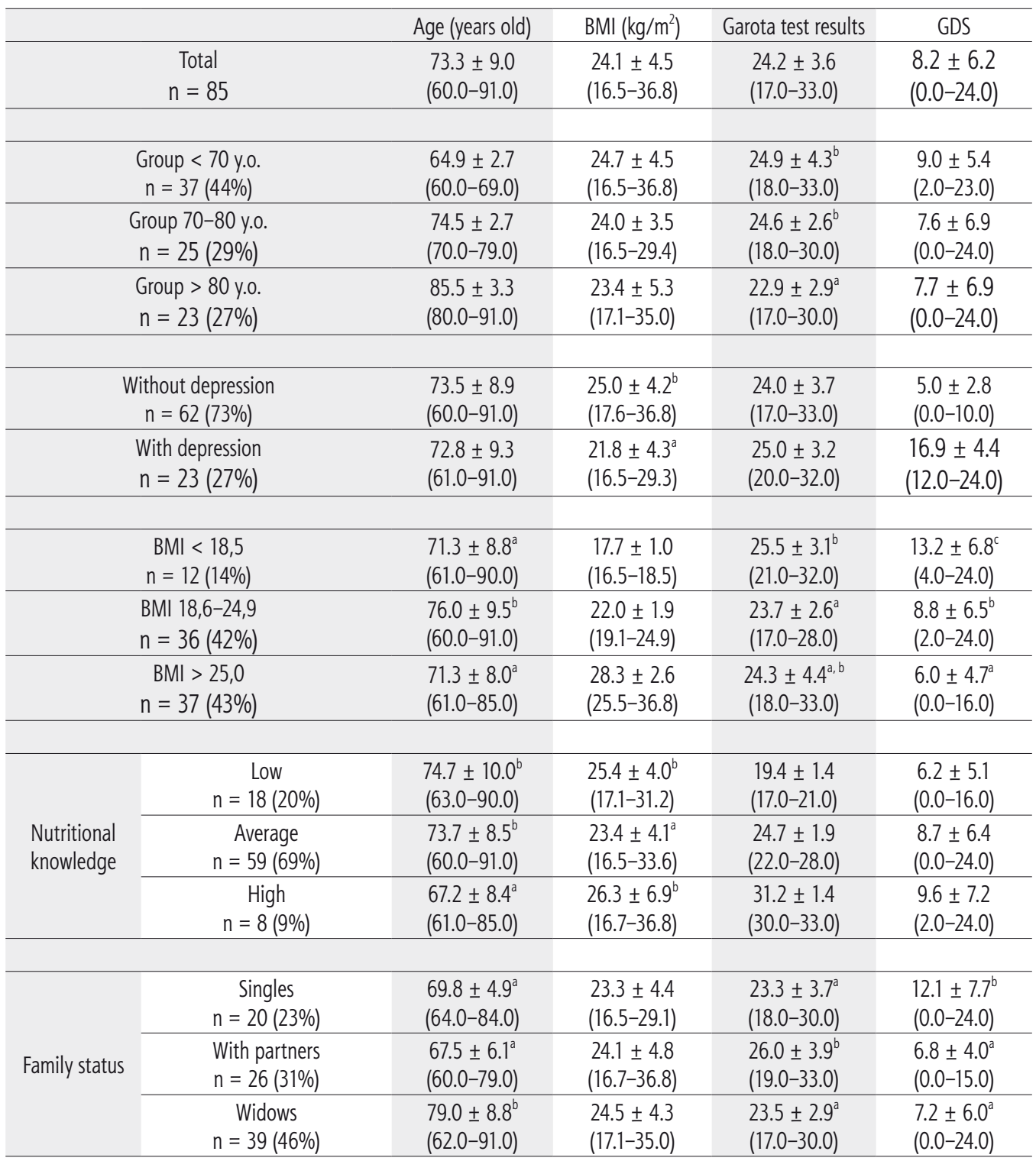

$a, b$, the significant differences between means

edge of the oldest seniors with their result in the GAROTA test $(p<0.05)$ on the level of $22.9 \pm 2.9(17-30)$ was slightly smaller as compared to seniors from other age groups (average of approx. $24.7 \pm 3.0 ; 18-33$ ).

Depression was diagnosed in $27 \%$ of the participants, while most seniors complained of some depression symptoms (Tabela 1). 6 women were diagnosed with moderate depression. There were no statistical differences between women with diagnosed depression and the rest of seniors in terms of their age and level of nutritional knowledge. Statistically lower $(p<0.01)$ average BMI $\left(21.8 \pm 4.3 \mathrm{~kg} / \mathrm{m}^{2}\right)$ was observed in women with depression than in the rest of women $(25.0 \pm$ $4.2 \mathrm{~kg} / \mathrm{m}^{2}$ ).

A similar percentage of seniors examined (approx. $40 \%$ ) was overweight or had a proper BMI. A lower
BMI was observed in $14 \%$ of women, who had greater nutritional knowledge (mean 25.5) and a GDS result (mean 13.2) that would indicate mild depression as compared with women with proper BMI and overweight (women who attained 23.7 and 24.3 points in the GAROTA test respectively, and 8.8 and 6.0 in the GDS). Overweight women showed smaller symptoms of depression than women with proper BMI and underweight ( $p<0.05$ and $p<0.01$ respectively).

Analysis of the nutritional knowledge showed that about $70 \%$ of respondents had a medium level of such knowledge and in only $9 \%$ of them this level of knowledge was high. People with high results in the GAROTA test were significantly younger that those with average and low results $(p<0.05)$ and had a bigger BMI $(p<0.05)$ as compared to people with average nutri- 
Table 2. Percentage distribution of the examined population with or without depression in relation to the nutritional status, nutritional knowledge and family status

\begin{tabular}{|c|c|c|c|}
\hline & & With depression & Without depression \\
\hline \multirow{3}{*}{$\begin{array}{c}\text { Nutritional status as } \\
\text { a BMI }\end{array}$} & Below normal & 22 & 8 \\
\hline & Normal & 52 & 39 \\
\hline & Overweight & 26 & 53 \\
\hline \multicolumn{2}{|c|}{ Statistic } & \multicolumn{2}{|c|}{$\begin{array}{l}\chi^{2}=17.62 \\
p<0.001\end{array}$} \\
\hline \multirow{3}{*}{ Nutritional knowledge } & Low & 44 & 55 \\
\hline & Average & 56 & 42 \\
\hline & High & 0 & 3 \\
\hline \multicolumn{2}{|c|}{ Statistic } & \multicolumn{2}{|c|}{$\begin{array}{l}\chi^{2}=6.22 \\
p<0.05\end{array}$} \\
\hline \multirow{3}{*}{ Family status } & Singles & $44\left(50^{*}\right)$ & $16\left(50^{*}\right)$ \\
\hline & Women with partners & $17\left(25^{*}\right)$ & $36\left(75^{*}\right)$ \\
\hline & Singles widows & $39\left(23^{*}\right)$ & $48\left(77^{*}\right)$ \\
\hline \multicolumn{2}{|c|}{ Statistic } & \multicolumn{2}{|c|}{$\begin{array}{l}\chi^{2}=20.81 \\
p<0.001\end{array}$} \\
\hline
\end{tabular}

${ }^{*}{ }^{*}$ the frequency occurrence of depression in singles, singles widows and women living with their partners $(\chi 2=20.58 ; p<0.001)$

tional knowledge and a BMI similar to people with low test results. There were no differences between the groups with different levels of nutritional knowledge to the extent of moderate depression symptoms.

Table 2 presents a percentage distribution of seniors with and without diagnosed depression in relation to the BMI and nutritional knowledge. There is a statistically significant difference between the groups with and without depression in both analyzed parameters ( $p<0.001$ and $p<0.05$ respectively). A greater number of seniors with depression was underweight $(22 \%)$ as compared to women without emotional disorders (8\%). Most people not diagnosed with depression were overweight (53\%), while only $26 \%$ of people with depression had a bigger BMI.

The majority of seniors with depression had an average $(56 \%)$ and low (44\%) level of nutritional knowledge, while most seniors without depression (55\%) had a low and average level of knowledge (42\%). People with high level of nutritional knowledge were found only in this group.

The foregoing paper also examines the influence of family status on the analysed parameters. $46 \%$ of seniors were widows living alone (Table 1), which had an average life expectancy (79.0 \pm 8.8 years) as compared to single women (respectively: $23 \% ; 69.8 \pm 4.9$ years) and women in relationships $(31 \% ; 67.5 \pm 6.1$ years, respectively). The analysis of nutritional knowledge showed that women living with partners have greater knowledge $(p<0.01)$ than single women or widows living on their own (average result of GARO-
TA test: $26.0 \pm 3.9$ vs. approx. $23.0 \pm 3.5$, respectively). The biggest statistical difference $(p<0.001)$ in expressing depression diagnosed with a GDS and confirmed with an individual diagnosis was found between single ladies and seniors living with their partners and widows $(12.1 \pm 7.7$ vs. approx. $7.0 \pm 5.0$, respectively). This relationship was confirmed by the analysis of the percentage distribution of people with diagnosed depression in relation to their family status and people with various family status - in relation to diagnosed depression (Table 2). Among seniors with diagnosed depression $83 \%$ (44 vs. 39\%, respectively) were women - single women and widows. Widows and seniors in relationships showed no signs of depression (48 vs. $36 \%$ respectively). Presented distribution differences were extremely significant $(p<0.001)$. Analysis of the occurrence of depression in relation to a person's family status $(p<0.001)$ confirmed that $50 \%$ of single seniors were diagnosed with depression, while in case of women in relationships and widows depression was diagnosed in only $25 \%$ of them.

\section{Discussion}

Examining depression in elderly people is extremely difficult due to the insufficient number of diagnostic criteria and multiple factors of the disease to be considered. The causes of depression in seniors are related to decreased physical fitness and to how seniors themselves describe the change in their quality of life. Some authors $[1,2,5]$ declare that depression is the 
most common mental disorder of the elderly. However evaluation of its frequency varies from 4 to $40 \%$. For example, Babiaczyk et al. [5] analyzed a group of over 200 people over 65 and found that over 50\% of the examined group showed signs of depression. They did not show statistical differences between light depression in women and men (approx. 40\%), whereas a greater number of women (14\%) suffered from deep depression as compared to men (approx. $2 \%$ ). Different data can be found in the research of Pacjan et al. [2], which showed that 19\% from among 70 examined people suffered from depression. Different data was obtained from the research of Walkiewicz et al. [6], where light depression was observed in $75 \%$ of examined women. However, the latter data were based only on examining 16 seniors.

In the foregoing paper depression was diagnosed in $23 \%$ of examined seniors. Intensified depression, based on the average number of points in the depression scale, did not depend on the age of the examined but significantly differed depending on the state of nutrition evaluated based on the BMI and on the method of nutrition, evaluated based on the level of nutritional knowledge. Intensified mood disorders in seniors with the lowest BMI were statistically more frequent than in women with proper BMI and twice as high as compared to women with excess weight. Significant intensification of depression was also observed in women with proper body weight rather than in overweight women. Analysis of the answers in the nutritional knowledge test showed that elderly people with the lowest body weight had the highest nutritional knowledge. No significant correlation between the points obtained in the test and intensity of depression was observed, whereas there was a significant, yet small $(p<0.05)$, negative correlation between women's BMI and the number of points in the depression scale.

Scientific papers often present depression as a disease that accompanies nutrition disorders, particularly anorexia [17, 19, 20, 22]. Literature presents no information about anorexia or other nutritional disorders in seniors. Researchers mostly concentrate of the co-existence of overweight and obesity in the elderly age as disorders resulting from the change of metabolism in seniors, as well as from the risk factors of many diseases diagnosed in the old age $[8,13]$. Correlation between BMI, depression and nutritional knowledge presented in the foregoing paper proves that nutritional disorders in seniors should be further investigated. The work of Walkiewicz et al. [6] evaluated the co-existence of depression and anaemia caused by iron defi- ciency. Although the authors showed no statistical relation between the foregoing parameters, possibly due to a small number of examined seniors, they were able to diagnose anaemia in $67 \%$ of women. Many papers present a relation between anaemia and iron deficiency with not eating properly, which is characteristic for eating and mood disorders, including depression [17, 18, 19, 22].

Analysis of population distribution seems to confirm a strong relationship between the level of nourishment in the elderly people and depression. Seniors with such disorders are neither over- or underweight (approx. 20\%), while $50 \%$ of women with no signs of depression were overweight and only $8 \%$ were underweight. The majority of seniors with depression also showed higher nutritional knowledge. Once again the broadly discussed issue that nutritional knowledge does not always mean good nutrition is confirmed [11, $21,22]$. This is particularly the case with people suffering from eating disorders, who often have proper knowledge, which is significantly higher than in the rest of society.

It is also worth mentioning that with elderly people eating disorders may not be similar to those diagnosed in young people. Our own clinical research shows that aversion to food, particularly in the elderly age, is characteristic for people who have problems with chewing and swallowing due to the dysfunction of taste buds, who suffer from gastrointestinal disorders and for some people with dementia. Koczorowska and Jundziłł-Bieniek [9] emphasized the relations between depression and the condition of teeth, indicating that seniors with depression find it hard to adapt to prosthetic restauration and how missing teeth influence the initiation of a disease.

The foregoing paper also investigated the influence of family status on mental disorders, as well as the difference in family status between seniors with and without depression. Pursuant to literature data [22, 23] most significant symptoms of depression were visible in lonely women as compared to seniors living with partners or widows. Even though among women with depression there is the same number of women who were never in a relationship and widows living alone, the number of singles with depression was significantly higher than with women from other subgroups (50\% vs. $20 \%$ ).

To sum up, the observed relationship between depression and low body weight, therefore low BMI and higher nutritional knowledge may suggest that seniors suffer from restrictive eating disorders that 
may be observed in other age groups. Therefore, it seems that conducting research aimed at determining detailed causes of this issue and implementing proper preventive programs. Interdisciplinary cooperation of gerontologists, psychologists and dieticians is extremely important and may improve the quality of life of the elderly people.

\section{Acknowledgements}

\section{Conflict of interest statement}

The authors declare no conflict of interest.

\section{Funding sources}

Part of the paper was prepared as part of the UnderstAID project, which is a platform that supports and helps people take care of their relatives suffering from dementia, $A A L$ 5/1/2013.

\section{References}

1. Dudek D, Zięba A, Siwek M, Wrobel A. Depression. In: Grodzicki T, Kocemba J, Skalska A (eds.). Geriatrics with elements of basic gerontology. Via Medica, Gdańsk. 2007; p. 108-112.

2. Pacjan A, Kulik TB, Chruściel P, Mazurek-Sitarz M, Sitarz K, Derewiecki T. Quality of life and the risk of the depression in obesity elderly people. Hygeia Public Health. 2014;49(4):820-824.

3. Eurostat. Population structure and ageing. http:// ec.europa.eu/eurostat/statistics-explained/index.php (access: 2015.04.26).

4. Polish Main Department of Statistics: The prognoses of inhabitants in years: 2008-2035. http://stat.gov.pl/ cps/rde/xbcr/gus/PUBL_L_prognoza_ludnosci_na_lata 2008_2035.pdp (access: 2015.04.26).

5. Babiarczyk B, Schlegel-Zawadzka M, Turbiarz A. The assessment of the depression symptoms frequency in the population of above 65 years old people. Med Og Nauk Zdr. 2013;19(4):453-457.

6. Walkiewicz K, Gętek M, Fizia K, Muc-Wierzgon M, Kokot T, Nowakowska-Zajdel E. The occurrence of anaemia and iron deficiency in elderly patients with emotional disturbances. Pol Nursing. 2014;52(2):130-134.

7. Bizdan L. Depression symptoms in elderly. Medycyna Wieku Podeszłego. 2011;1(1):31-41.

8. Górecka D, Czarnocińska J, Owczarzak R. The frequency of food products consumption in elderly people according to their area of living. Probl Hig Epidemiol. 2011;92(4):955959.

9. Koczorowski R, Jundziłł-Bieniek E. The occurrence of depression symptoms in elderly people and their influence on the adaptation to the prosthetic restorations. Protet Stomatol. 2009;59(4):236-241.

10. Rosenberg I, Miller J. Nutritional factors in physical and cognitive function of elderly people. Am J Clin Nutr. 1992;55:12375-12435.

11. Lin W, Lee YW. Nutrition knowledge, attitudes and dietary restriction behaviour of the Taiwanese elderly. Asia Pac J Clin Nutr. 2005;14(3):221-229.
12. Benton D, Donohoe R. The effect of nutrients on mood. Public Health Nutr. 1999;2:403-409.

13. Payette $H$, Shatenstein B. Determinants of healthy eating in community-dwelling elderly people. Can J Pub Health. 2005;3:27-31.

14. Pysz-Izdebska K, Leszczyńska T, Kopeć A, Nowacka E, Bugaj $B$. The energy and nutritional components intake in the daily food rations in boarders of social home and the assessment of the anthropometric parameters of theirs. Żywność, Nauka, Technologia, Jakość. 2010;73(6):239254.

15. Albiński R, Kleszczewska-Albińska A, Bedyńska S. Geriatric Scale Of Depression (GDS). The accuracy and reliability of various forms of this test - a review of research. Psychiatria Polska. 2011;45(4):555-562.

16. Yesavage JA, Brink TL, Rose TL, Lum O, Huang V, Adey $\mathrm{M}$, Leirer VO. Development and validation of a geriatric depression screening scale: a preliminary report. J Psych Res. 1983;17:37-49.

17. Wójciak RW. Effect of short-term food restriction on iron metabolism, relative well-being and depression symptoms in healthy women. Eating and Weight Disorders - Studies on Anorexia, Bulimia and Obesity. 2014;19(3):321-327.

18. Wójciak RW. The assessment of food restrictions on the iron status in animal models and human anorexia. Trace Elements and Electrolytes. 2014;31(3):108-115.

19. Wójciak RW, Mojs E, Michalska MM, Samulak D. The free-will starvation in women during pregnancy and the postpartum level of serum iron - the preliminary research. Probl Hig Epidemiol. 2013;94(4):893-896.

20. Wojciak RW, Gawecki J. The occurrence of anorexic behaviors in young women. In: Janowski $K$, Steuden $S$, editors. Biopsychosocial aspects of health and disease, vol. 1. Bestprint, Lublin 2009; p. 207-217.

21. Gawęcki J, Czarnocińska J, Kulczak M. Test for assessment and evaluated the nutritional knowledge "GAROTA". University of Life Sciences Press, Poznań 2012.

22. Michalak J, Zhank XC, Jacobi F. Vegetarian diet and mental disorders: results from a representative community survey. Int J Behav Nutr Phys Act. 2012;9:67-77.

23. Zamani SN, Bagheri M, Abbas Nejad M. Investigation of the demographic characteristics and mental health in self-immolation attempters. Int J High Risk Behav Addict. 2013;2(2):77-81.

Acceptance for editing: 2016-06-10 Acceptance for publication: 2016-06-23

Correspondence address: Rafał W. Wójciak Department of Clinical Psychology Poznan University of Medical Sciences 70 Bukowska Str, 60-812 Poznań, Poland phone/fax: +48618547274 email: rafwoj@ump.edu.pl 